Sebastián Edwards, American Default (New Jersey: Princeton University Press, 2018).

\author{
RESEÑA
}

\title{
LA CASA DE PAPEL
}

\author{
Alfredo Bullard G. \\ Pontificia Universidad Católica del Perú
}

\section{UN ATRACO MUY PARTICULAR}

I a exitosa serie de televisión española La casa de papel relata un atraco singular. Un grupo de delincuentes, liderados por un personaje que se hace llamar "El Profesor", asalta la Fábrica Nacional de Moneda y Timbre de España, donde se imprimen los billetes de euros que se ponen en circulación en dicho país.

Ellos no se sienten ladrones. No piensan llevarse el dinero que encuentren en las bóvedas. El plan es secuestrar la casa de Moneda por el mayor tiempo posible para imprimir su propio dinero ( 984 millones de euros) y luego escapar.

En su imaginario no le están robando a nadie. Se hacen millonarios sin quitarles a otros lo que es suyo. En una de las escenas críticas de la serie, El Profesor busca persuadir a la inspectora Raquel Murillo, la policía que lo venía persiguiendo, sobre por qué ellos no eran los malos de la historia. Dice:

Te han enseñado a verlo todo incompleto de buenos y malos.

Pero esto que estamos haciendo nosotros sí que te parece bien

\footnotetext{
Alfredo Bullard G. Abogado de la Pontificia Universidad Católica del Perú. Máster en derecho por la Universidad de Yale. Presidió el Tribunal del Instituto Nacional de Defensa de la Competencia y de Protección de la Propiedad Intelectual del Perú. Socio de Bullard, Falla \& Ezcurra. Profesor de derecho en la Pontificia Universidad Católica del Perú. Email: abullard@bullardabogados.pe.
} 
si lo hace otra gente. En el año 2011, el Banco Central Europeo creó de la nada 171.000 millones de euros. De la nada. Igual que estamos haciendo nosotros. Sólo que a lo grande. 185.000 en el 2012. 145.000 millones de euros en el 2013. ¿Sabes adónde fue a parar todo ese dinero? A los bancos. Directamente de la fábrica a los más ricos. ¿Dijo alguien que el Banco Central Europeo fuera un ladrón? Inyección de liquidez lo llamaron. Y lo sacaron de la nada Raquel, de la nada.

¿Qué es esto? [Mostrándole un billete de 50 euros] Esto no es nada, Raquel, esto es papel. [rompiendo el billete] Es papel, ¿lo ves? Es papel. Yo estoy haciendo una inyección de liquidez. Pero no a la banca, la estoy haciendo aquí, en la economía real de este grupo de desgraciados, que es lo que somos Raquel.

Más allá de la ficción, un economista sabe que en realidad sí están robando. Imprimir dinero sin respaldo y ponerlo en circulación, como lo hace la banda del Profesor, tiene un efecto similar a un robo, más allá de la singular naturaleza del atraco. Lo curioso es que los gobiernos de todo el mundo hacen algo similar y también, en su propio imaginario, no nos están robando.

Al imprimir dinero sin sustento y ponerlo en circulación están sustrayendo el valor del dinero de los demás ciudadanos. Lo están devaluando. Se hacen más ricos, pero al hacerlo hacen más pobres a otros. No necesitan meterle la mano al bolsillo a nadie para robar. No necesitan sustraerle billetes a nadie. Le están sustrayendo su valor. El valor de la moneda que otros tengan en ese bolsillo se reduce como por arte de magia, aunque la magia puede ser fácilmente explicada.

El Profesor trata de justificar sus acciones diciendo que el Banco Central Europeo es el verdaderamente malo, porque inyectó muchísimos más euros de los que él y sus secuaces van a inyectar a la economía. Más allá de la magnitud, cualitativamente el efecto es el mismo.

Pero la ley parece hacer la diferencia. Los atracadores de la Fábrica Nacional de Moneda y Timbre son perseguidos por la policía. No están legalmente autorizados para hacer lo que hacen, a margen de que, en estricto rigor, el impacto económico puede ser similar. Los funcionarios de un Banco Central no temen hacer lo mismo. Lo hacen legalmente, en base a facultades jurídicamente definidas. El Estado puede enriquecerse a costa de los individuos, pero los individuos no pueden hacerlo a costa 
de otros individuos. Y, a pesar de que las consecuencias económicas son las mismas, las legales no lo son.

Algo similar puede ocurrir cuando un Estado desconoce sus propias obligaciones usando medios aparentemente legales. En contraste con lo que ocurre con un privado que incumple con sus obligaciones contractuales, los gobiernos suelen encontrar formas de hacer lo mismo bajo la apariencia de legalidad. Declaran la moratoria de sus obligaciones, modifican los precios o las tasas de interés, devalúan la moneda con la que deben honrar una deuda. O simplemente declaran que un contrato ya no es exigible según sus términos, prohibiendo la aplicación de los mecanismos de indexación pactados para proteger el valor de una acreencia.

Si un privado hiciera lo mismo las consecuencias jurídicas serían radicalmente distintas. Se sometería a acciones legales o judiciales definidas para sancionar sus incumplimientos: ejecución forzada de la obligación, desconocimiento de efectos legales a su conducta, pago de daños por perjuicios, etcétera.

La teoría dice que al Estado le debería pasar lo mismo. Pero el Estado tiene el monopolio del uso de la ley, y lo puede usar para cambiar las reglas del juego haciendo lo mismo pero legalmente.

De esta doble personalidad del Estado, de esta esquizofrenia jurídica en que el derecho hace con una mano lo que deshace con la otra, se trata el libro de Sebastián Edwards American Default ${ }^{1}$.

El libro de Edwards relata la relevante y virtualmente desconocida historia de Franklin Delano Roosevelt (FDR), el Congreso, la Corte Suprema y la batalla por el oro (y el abandono del patrón oro en los Estados Unidos). Leyendo la historia relatada en el libro uno descubre que La casa de papel, y sus derivadas, más allá del efecto cinematográfico, no es tan singular y extraña como uno podría pensar.

\section{LA HISTORIA JAMÁS CONTADA (AL MENOS DE ESA MANERA)}

Un Estado enfrenta una severa crisis económica. Los precios se deprimen, el desempleo de multiplica. La desazón y la desesperanza campean. Las reglas del juego estorban. Estas reglas incluyen la propiedad

${ }^{1}$ Sebastián Edwards, American Default (New Jersey: Princeton University Press, 2018). En adelante, el libro se citará tan sólo con su número de página entre paréntesis. 
de los ciudadanos sobre sus bienes, sobre su dinero, sobre sus depósitos y el respeto a los contratos que tienen celebrados y cuyos términos deben ser cumplidos. También incluyen los límites al Estado para manejar la moneda y su valor.

Esas reglas, sin embargo, no son sólo de titularidad del Estado ni han sido creadas sólo en su beneficio. Son de todos y cada uno de los ciudadanos y de las empresas que a fin de cuentas recogen las inversiones de tales ciudadanos. De hecho, son, antes que derechos del Estado, límites a su actuación. El intrincado sistema jurídico brinda protección a esas reglas. Algunas incluso se las protege a nivel constitucional.

Pero las reglas estorban para poder adoptar ciertas soluciones urgentes. Finalmente los bomberos pueden romper la puerta del vecino (afectando su propiedad) para apagar un incendio o la policía actuar bajo estado de sitio para controlar serios disturbios al orden público, limitando los derechos individuales. O, al menos, son ésas las analogías que se suelen usar.

Cuando el Estado decide entonces romper las reglas que justamente limitan su acción recurre a un discurso en el que la gravedad de la situación permite que los fines justifiquen los medios. Toman los ahorros de la gente o los licuan. Expropian sus bienes. Reducen el valor de su dinero devaluándolo. Modifican los contratos para que los acreedores tengan menos y los deudores tengan más, a pesar de que el más y el menos contradicen lo que las partes acordaron. Incluso limitan las obligaciones del propio Estado con sus acreedores, haciendo que el deudor pueda eliminar sus obligaciones.

En Latinoamérica ello no es novedad. La falta de institucionalidad nos trae problemas, pero también respuestas "desinstitucionalizadas". El gobierno hace y deshace y se autojustifica. Allí está el caso de Argentina y su corralito. Ningún país de los nuestros se libra. Todos han tenido, con matices, incidentes similares de mayor o menor magnitud.

Se toman medidas de ajuste que en realidad son desajustes de las reglas en base a las cuales los ciudadanos invirtieron y ahorraron. La señal es que las reglas no son confiables y, como tales, están hechas para romperse. En paralelo, los países supuestamente institucionalizados se rasgan las vestiduras y saltan a proteger a sus inversionistas, exigiendo mesura e implantando mecanismos de protección, los que van desde la intervención diplomática a mecanismos internacionales de protección de inversiones, como los arbitrajes. 
Pero todo ello es imaginado (y vivido) en países de baja institucionalidad, países poco serios o que dejan de serlo rápidamente (es decir, no eran tan serios como parecían).

Sebastián Edwards nos cuenta la misma historia, pero no en un "país bananero" o poco institucionalizado. La cuenta para Estados Unidos, durante la crisis de 1933, año en que FDR toma el poder. Estados Unidos hizo algo muy similar a lo que hizo Argentina con el corralito: rompió las reglas del juego y la confianza que esas reglas estaban destinadas a proteger.

La historia es sorprendente. Los detalles que Edwards nos entrega de un episodio tan poco conocido son reveladores de las grandes semejanzas (y también de las muchas diferencias) con lo que ha ocurrido en nuestros países.

El significado histórico de los eventos dejó como herencia el abandono del patrón oro como sistema que protegía el valor del dinero. El oro se volvió en los Estados Unidos, como los productos de primera necesidad en algunos países, un bien del que se justificaba su control, su expropiación por el Estado y el control de su precio. El quitarle el valor al dinero (la devaluación) se vuelve un mecanismo legítimo para levantar los precios y proteger a los productores, en especial a los agricultores. Y el oro es expropiado de los ciudadanos, quienes son obligados a venderlo bajo pena de cárcel, con excepción de sus dientes y sus joyas personales.

Los autores intelectuales de la medida llegaron a decir que el abandono del patrón oro sería celebrado “...como un Segundo Día de la Independencia porque es una de las pocas fechas importantes de nuestra historia" (59). Tal predicción nunca se cumplió.

Los ahorros se controlaron y se decretaron feriados bancarios para poder quitarles el valor a los depósitos de las personas sin posibilidad de que se defendieran retirándolos.

Pero lo más asombroso, quizás el mayor ataque a la institucionalidad establecida (y lo más desconocido del episodio), es que los Estados Unidos modificaron los contratos y alteraron los términos de los mismos. Modificaron "el precio" de dichos contratos, prohibiendo la aplicación de las cláusulas que indexaban al oro las obligaciones. Y es que no se podía lograr el control que se buscaba mediante el manejo monetario sin controlar el valor de los contratos cuyas obligaciones se pagarían con dicho dinero. 
En este camino el Estado muestra sus dos caras: la de monopolista de la ley y la de deudor. Con la primera cambia las reglas bajo las cuales se endeudó, y con ello se libera de parte de sus obligaciones. Como en La casa de papel, puede hacer legalmente lo que para el común de los mortales sería una ilegalidad. La pregunta moral fundamental que se planteó en su momento al Congreso norteamericano fue si “...la solemnidad de un contrato puede ser alterada cuando a juicio de los representantes del pueblo su bienestar lo exige" (62).

Una pregunta similar en Perú, en el año 1993, llevó a introducir el artículo 62 de la Constitución, según el cual "los términos contractuales no pueden ser modificados por leyes u otras disposiciones de cualquier clase", norma pensada precisamente para evitar que ocurra lo que Edwards describe ocurrió en el Estados Unidos de FDR. Pero este país no tenía (al menos expresamente) una disposición tan clara. Y viendo el relato de Edwards sobre las acciones de FDR, sus asesores, el Congreso y la Corte Suprema, uno se pregunta si, de haberla tenido, las cosas hubieran sido realmente diferentes.

\section{EL STORYTELLING}

Los libros de economía, como los de derecho, suelen ser aburridos. Un libro de derecho y de economía puede ser doblemente aburrido.

Pero lo importante para transmitir una idea es el storytelling; es decir, la capacidad de contar una historia. No importa sobre qué hablemos o escribamos. Todo puede ser contado como un cuento. Las personas no recuerdan hechos. Recuerdan relatos.

Edwards entiende muy bien esta idea. La descripción de cada uno de los personajes, su backround, hasta los chismes de su vida personal y la interacción de todos ellos están relatados de manera notable. Cada uno es dibujado en su faceta humana y, en algunos, con su cuota de pretensión divina de poder cambiar el mundo a uno distinto con sólo decidirlo.

Soy un convencido de que la creación y destrucción de las instituciones nacen de la interacción de miles o millones de individuos. Pero los personajes son importantes para entender cómo se plasman y son recogidas esas interacciones. Nunca esa interacción puede ser totalmente impersonal. Y muchas veces es centralmente personal. Si bien las 
instituciones nacen del desorden ordenado espontáneamente por la interacción, el conjunto de anécdotas al que llamamos historia les da cara a ese orden y desorden. Con ello el libro engancha al lector y lo atrapa en un lenguaje que tiene el mérito de ser, al mismo tiempo, coloquial y técnico.

Con la información de la investigación de Edwards pudieron escribirse muchos libros distintos. Pudo escribirse un libro de análisis económico, en el que, usando sólo estadísticas, data y matemática, nos demostrara lo que quería demostrar. Pudo ser un libro conceptual sin mucha historia, reemplazando buena parte de los números con la descripción de lo que ellos reflejan. O pudo centrarse en un análisis exclusivamente jurídico de lo que pasó.

Pero optó por novelar la historia. Les dio cara - y alma- a las decisiones: quién era FDR, quiénes sus asesores y miembros de su gobierno, quiénes los congresistas que "cocinaron" las normas que finalmente se aprobaron para cambiar las reglas, quiénes los magistrados de la Corte Suprema que validaron la conculcación de los derechos. Y quiénes se opusieron y combatieron los cambios. Quiénes ganaron y quiénes perdieron. Quiénes hicieron lobby de uno y otro lado.

Su abordaje no pudo ser más acertado. Edwards opta por novelar la historia sin renunciar al rigor académico. La razón por la que los lectores prefieren una historia a una descripción de hechos es porque nos gusta que lo real se sienta vívido. Tanto la ficción como la realidad tienen que sonar verosímiles para capturar la lectura. Los economistas suelen olvidar que lidian con la realidad. El lenguaje económico suele sonar a ficción inverosímil, no porque lo sea, sino porque mira la realidad desde arriba, en lugar de meterse en el pellejo de quienes la protagonizan.

En contraste, recurrir a los medios que usa la ficción para hacer creíble una historia puede, paradójicamente, devolverle realidad a la economía. Y ni qué decir del derecho. Las personas de carne y hueso entienden mejor a los abogados en las películas que en el mundo real. Lo mismo puede pasar con los economistas cuando la economía se explica como un relato. La economía se vuelve tangible y lo que se cuenta aparece como más relevante.

En el arte de explicar, la forma puede ser tanto o más importante que el fondo de lo que se cuenta. La forma escogida por Edwards es 
uno de los grandes aciertos del libro. Es un libro entretenido. Un libro con varias historias dentro de la historia. En cada historia uno puede detenerse a ver el paisaje del camino, sin perjuicio de que es el panorama general lo que realmente importa. Y todas esas historias están muy bien contadas.

\section{DERECHO Y ECONOMÍA}

El libro muestra la importancia de unir el derecho con la economía.

Salvo algunos episodios aislados, antes de la mitad del siglo pasado los economistas y los abogados vivieron divorciados por décadas. El resultado fue que juristas y abogados no entendían las consecuencias de las leyes en la realidad. De manera parecida, los economistas no entendían las reglas que generan la institucionalidad bajo la cual se toman las decisiones económicas.

En general, los economistas vieron a los abogados como formalistas, con poca sustancia real y mucha esgrima conceptual sin contenido ni relevancia. Por su parte, los abogados ven a los economistas como eficientistas, desapegados de valores relevantes como la justicia.

Afortunadamente ello cambió hace más de sesenta años. El trabajo de Edwards es un fiel testimonio de por qué agradecer ese cambio.

Tomo varias décadas para que se descubriera el nivel de complementariedad de ambas formas de conocimiento. Sin reglas, no hay economía posible. Y sin economía, no se puede entender por qué las reglas deben ser de cierta manera y cuáles son las consecuencias de que no sea así.

El relato del libro da clara cuenta de las ventajas de entender las cosas de esa manera. Edwards se muestra como un economista preocupado por el derecho, que sabe que su relevancia puede ser en ocasiones incluso mayor que las herramientas metodológicas de la economía para entender por qué pasan las cosas.

O dicho de otra manera, un economista cuya mochila de viaje no tiene una comprensión básica del derecho está condenado a fracasar en muchas de sus aventuras intelectuales. Y a un abogado le puede pasar lo mismo si no tiene en su mochila herramientas básicas de economía. Finalmente, las instituciones no son otra cosa que las hijas del matrimonio del derecho y la economía. 


\section{5. ¿Y QUÉ PASÓ CON LAS INSTITUCIONES?}

En la ortodoxia institucional - a lo Douglas North-, la relación entre el derecho y la economía se explica de manera relativamente sencilla. Existen unas reglas del juego muy simples, cuya presencia es esencial para el desarrollo: la propiedad debe protegerse, la palabra empeñada debe respetarse y las externalidades deben internalizarse. Sin esas reglas las cosas no funcionan bien.

Bajo tal perspectiva, la diferencia entre los países desarrollados y los subdesarrollados (sea lo que sea que signifique esa distinción) se explica con asombrosa simplicidad: los primeros tienen instituciones. Los segundos, no.

Los primeros respetan la propiedad y los contratos y tienen sistemas creíbles de asignación de riesgo legales que internalizan las consecuencias positivas y negativas de toda conducta.

Si se sale de la receta, la torta se quemará en el horno y la sociedad se alejará de la utopía que queremos alcanzar y se acercará a la distopía que queremos evitar. Esa ortodoxia explica la rigurosidad que muchas veces se persigue en países subdesarrollados en la creación de instituciones como el medio y el fin de romper el estancamiento y la pérdida de bienestar.

La predicción ortodoxa es que quien no sigue ese camino será castigado. No puedes destruir la propiedad y los contratos sin pagar los platos rotos. Las señales harán cambiar la conducta hacia lo perverso y regresivo. Si le quitas a alguien su propiedad convertirás al resto de los dueños en propietarios de algo que, de alguna manera, se vuelve común; es decir, en no propiedad. La pérdida de uno se convierte en riesgo para los otros. Si a alguien le quitas su oro, los propietarios de otros bienes sentirán que también les has quitado parte de lo que es suyo, porque pueden ser los siguientes.

Si destruyes lo pactado, la palabra empeñada también pierde valor. Los contratos como medios de colaboración se debilitan, y ya no generarán la confianza que antes generaban. La gente vende y presta menos cuando sabe que lo que acordó podría no ser respetado. Los costos de transacción se elevarán y, con ello, el número de transacciones se reducirá. Para quienes creemos que más transacciones aumentan el bienestar, el resultado va a contramano de lo que una sociedad debería desear para sí. 
Como indica Edwards, el profesor sueco Gustav Cassel, una de las autoridades más reputadas en asuntos monetarios de la época, sentenció que la legislación promovida por FDR “...violaba la santidad de los contratos y disminuiría los derechos de propiedad alrededor del mundo. Esto, añadió, reducirá los ahorros y la inversión y dañaría la formación de capital y el progreso y el crecimiento económico" (74). Esa predicción, sin embargo, tampoco se cumplió.

Así como el deudor que no paga pierde crédito, un Estado que cambia las reglas se vuelve poco confiable e inestable. Creo que eso es lo que conduce a Edwards a estudiar el caso de American Default. Un país reputado, una economía importante se arriesga en un juego que a otros no les está permitido. Juega con la institucionalidad. Desafía esas reglas simples que en principio, bajo la receta ortodoxa, no se deben desafiar.

Y llama la atención que el modelo de predicción no parece cumplirse. Edwards da cuenta de que, a pesar de lo que dicen las predicciones y de lo difícil que es trabajar con data compleja (y que arroja resultados espurios), al buscar causalidad entre lo que ocurrió y sus consecuencias no parece encontrar indicios de que lo que hicieron FDR, el Congreso y la Corte Suprema le pasó la factura a los Estados Unidos.

Los indicadores analizados en el libro no muestran que al afectar las reglas del juego pactadas en los contratos se haya generado un descalabro institucional. No parece que el irrespeto a los contratos por parte de la Corte Suprema haya elevado los costos de transacción de la economía o retraído el número de transacciones. No hay evidencia de que Estados Unidos tuviera dificultades para encontrar crédito ni de que las tasas de interés subieran en sus contratos de préstamo. Parece que a Estados Unidos la afectación institucional no le pasó la factura como sí le ocurrió a Argentina a partir del año 2001.

\section{6. ¿POR QUÉ FUE ASÍ?}

¿Por qué Estados Unidos aparentemente no sufrió la consecuencia de sus actos? El libro no da una respuesta definitiva. Pero ensaya varias. Y es quizás, junto con el relato de la historia, lo más interesante y relevante.

La hipótesis de Edwards es que los ciudadanos e inversionistas entendieron que hay circunstancias en que las reglas tienen que romperse. Como se acepta que el bombero a veces tiene que romper la puerta 
o que la policía en una situación de emergencia tiene que detener a un individuo sin orden judicial, el Estado a veces puede tomar la propiedad ajena e intervenir en los contratos para atender a un fin mayor. Hay rupturas que se perdonan o, al menos, no se condenan con la misma intensidad dependiendo de las circunstancias.

Quizás nos están robando algo, pero el hambre a veces justifica ser tolerantes con la necesidad de tomar un mendrugo de pan (o varios billones de dólares en oro o el valor billonario de innumerables cláusulas contractuales).

Y ello es más cierto si el tomar el valor ajeno se produce dentro de un proceso institucionalizado.

Es interesante cómo, a lo largo de todo el relato recogido en American Default, se afectan ciertas reglas del juego pero sin salirse de otras reglas del juego. No se cierra el Congreso ni se nombran jueces a dedo. Hay negociación e intercambios. Pero todos se ajustan a las reglas en que tales negociaciones deben de darse: procesos democráticos, división de poderes, la existencia de una judicatura imparcial.

Si se va a hacer algo, por malo que sea, hay que hacerlo bien, entendiendo por "bien" hacerlo respetando ciertas reglas.

La decisión final la toma la Corte Suprema de los Estados Unidos. Los nombres de varios de sus integrantes son particularmente célebres. Se puede decir muchas cosas de lo que hicieron y, sobre todo, de lo que decidieron. Pero es una corte independiente y prestigiada. Se puede equivocar. Pero el error es el precio a pagar para que pueda acertar de manera independiente. Más que la esencia de lo que se decide, lo importante parece ser el cómo lo decide. El sistema parece preferir la decisión incorrecta en un proceso institucional que la correcta vulnerando la autonomía judicial.

Incluso, en medio del impacto institucional que significó la ley que anulaba las cláusulas indexadas al oro en los contratos pasados y futuros, norma que le permitía al Estado cambiar sus propias obligaciones crediticias, la Corte Suprema declaró que era inconstitucional, lo que implicaba calificar el acto como contrario a valores protegidos por la Constitución. Sin embargo, la Suprema salvó la decisión del gobierno diciendo que no se había probado cuál era el daño que se causó a los demandantes. A pesar del "tufillo" a triquiñuela legalista, al menos, en parte de su declaración, la Suprema sostuvo que era importante preservar las reglas del juego. 
A pesar de ello, McReynolds, uno de los magistrados disidentes, al argumentar su voto, señaló: "La Constitución como muchos de nosotros la entendemos, ese instrumento que ha significado tanto para nosotros, ha dejado de existir". Luego terminó diciendo: "La vergüenza y la humillación están sobre nosotros ahora. Podemos esperar con seguridad el caos moral y financiero" (178). Su predicción tampoco se cumplió.

El relato donde se muestra a FDR y sus asesores escuchando en total incertidumbre por teléfono la sentencia en la que, finalmente, se consagra la legalidad del default y el cambio de reglas muestra un Ejecutivo enfrentando la independencia de otro poder del Estado. Los ejercicios posibles de distintas salidas del problema legal antes de la sentencia muestran un proceso político en el que si bien hay que jugar el juego, éste no admite ciertas trampas. Era claro que FDR no sabía qué iba a ocurrir. La judicatura era independiente. De hecho, FDR fue derrotado en varias de las medidas del New Deal frente a la misma Corte, en algunos casos con decisiones unánimes, en esas mismas épocas. La Suprema no era dependiente del Presidente. Sólo que a veces coincidía y a veces discrepaba.

No siempre el juego tiene un buen resultado. La sentencia es realmente pobre en los argumentos y el resultado, al menos a mi criterio (y entiendo que en el de Edwards), equivocado. Pero es mejor para todos que el juego se dé dentro de las reglas. La institucionalidad del proceso de decisión parece más importante que la institucionalidad del resultado. Quizás es mejor perder algunos derechos en el camino si con ello se preserva la institucionalidad de procesos predecibles.

Sin embargo, ésa no es la única explicación posible. Hay explicaciones alternativas (o quizás complementarias).

Para quienes creemos que las instituciones tienen un origen evolutivo, no siempre las malas instituciones desaparecen o, por lo menos, no lo hacen en el corto plazo. De hecho, es parte del proceso evolutivo que sobrevivan y que su existencia no necesariamente cause los estropicios que predecimos.

Las instituciones son respuestas que el orden espontáneo, derivado de la interacción, encuentra a los problemas que enfrentamos. Suelen ser consecuencia de experimentación descentralizada entre miles o millones de individuos. Dicha espontaneidad toma a veces caminos insospechados, como puede ser la popularidad del Presidente o la desesperación ante circunstancias adversas. 
$\mathrm{Su}$ origen suele ser accidental. Alguien hace algo sin pensarlo y ese algo genera una consecuencia que aumenta la posibilidad de supervivencia de esa institución. La repetición de la conducta se convierte en regla del juego. Si la regla es buena se generaliza y sobrevive.

Como en la evolución biológica, la evolución social es de carácter adaptativo. No sobrevive el más fuerte, sino el que mejor se adapta a las circunstancias concretas que enfrenta.

Los zorros blancos sobreviven mejor en la nieve que los cafés no porque sean más fuertes o mejores, sino porque se adaptan mejor a un ambiente de color blanco que los oculta de sus presas y los protege de convertirse en presas de otros. Si la nieve desaparece, sus posibilidades de supervivencia se reducen y aumentan las de los zorros cafés.

Los zorros blancos no se vuelven de ese color por una decisión consciente o razonada. Una mutación genética (y accidental) aclara su pelaje y aumenta sus posibilidades de sobrevivir. Es un mero accidente. La "racionalidad" de su existencia no proviene de la voluntad de nadie, sino que de la unión de una mutación accidental y un ambiente propicio al que esa mutación se adapta.

Ello no significa que no pueda haber zorros cafés en la nieve, a pesar de que sus posibilidades de sobrevivir sean menores. La tendrán más difícil, pero quizá sobrevivan. De la misma manera, las malas instituciones sobreviven muchas veces al lado de la buenas por más tiempo del que esperaríamos.

Una afectación institucional debe verse - como las mutacionesen su circunstancia. No toda mutación menos adaptada conduce a la extinción inmediata. Es más. A veces, ciertas circunstancias particulares explican por qué sobrevivieron y se adaptaron a ellas. Sin embargo, en el largo plazo los zorros cafés tenderán a sobrevivir menos en la nieve que los blancos. En la realidad la adaptación no te condena a desaparecer. Sólo aumenta o reduce tus posibilidades de sobrevivir.

No respetar la propiedad o los contratos no conduce necesariamente a la destrucción institucional. Esa mutación puede sobrevivir, al menos por un tiempo. Quizás en ciertas circunstancias pueda hasta tener, temporalmente, efectos positivos. Pero una sociedad sin propiedad tendrá mayores problemas para transcender hacia un mayor bienestar en el largo plazo. 
Parecería claro que si el gobierno de Estados Unidos hubiera decidido repetir una y otra vez el juego de FDR el resultado se parecería más al de la Venezuela de Maduro.

Como en la evolución biológica, las mutaciones sociales pueden tener consecuencias insospechadas, algunas de las cuales no son totalmente consistentes con la teoría darwiniana. Pero, a la larga, la propiedad y el respeto a los contratos generarán sociedades más "resistentes a la extinción".

Lo que pasó con las políticas comentadas en el libro quizás pueda explicarse como parte de ese proceso evolutivo complejo, en el que no todas las políticas equivocadas generan efectos nocivos, como no todas las políticas correctas nos llevan a un mundo mejor. Las instituciones, como los genes, aumentan las posibilidades de supervivencia, pero no las aseguran para individuos o circunstancias concretas.

\section{FINALMENTE, ¿POR QUÉ LEER AMERICAN DEFAULT?}

¿Por qué, entonces, leer American Default?

Primero, porque es una historia interesante y muy bien contada.

Segundo, porque es una parte importante pero virtualmente olvidada de la historia de los Estados Unidos y de la economía mundial; una historia bastante extraña, que merece ser sacada del olvido.

Y tercero, porque es un libro que deja una profunda reflexión sobre la institucionalidad, su importancia y la necesidad de entenderla.

Refleja que, incluso en lo institucional, el dogmatismo debe ser tomado con pinzas. No todo lo que está mal hecho tiene malas consecuencias y no todo lo bien hecho genera bienestar.

Un querido profesor de derecho, Mario Pasco, dijo una vez en clases que "la economía era una ciencia de predicción del futuro, como la astrología o la quiromancia, sólo que menos exacta". De alguna manera tiene razón. El mundo es más complejo que una simple relación binaria en la que lo bueno significa mejor y lo malo significa peor. Pero, a su vez, eso no significa que no podamos pensar en las consecuencias de lo que hacemos. Toda acción tiene siempre algo de albur, algo de azar en sus consecuencias. Nada, afortunadamente, es cien por ciento predecible, pues de ser así la vida sería muy aburrida y los economistas y los abogados se quedarían sin trabajo. 
Pero ello no es justificación suficiente para jugar el destino de un país y de su gente a los dados. No siempre vamos a tener la misma suerte. El que muchas veces las recetas no se cumplan no es licencia para cocinar sin ellas. El que a veces la improvisación dé buenos resultados no es excusa para vivir improvisando. $E P$ 